Journal of Patient-Centered

10-28-2019

\title{
I Live Alone but Don't Feel Alone: Social Isolation and Loneliness From the Patient Perspective
}

\author{
Julia Bedard-Thomas \\ Christian Gausvik \\ Jonathan Wessels \\ Saundra Regan \\ Keesha Goodnow \\ Anna Goroncy
}

Follow this and additional works at: https://aah.org/jpcrr

Part of the Community Health and Preventive Medicine Commons, Family Medicine Commons, Geriatrics Commons, Mental and Social Health Commons, and the Primary Care Commons

\section{Recommended Citation}

Bedard-Thomas J, Gausvik C, Wessels J, Regan S, Goodnow K, Goroncy, A. I live alone but don't feel alone: social isolation and loneliness from the patient perspective. J Patient Cent Res Rev. 2019;6:262-6. doi: $10.17294 / 2330-0698.1715$

Published quarterly by Midwest-based health system Advocate Aurora Health and indexed in PubMed Central, the Journal of Patient-Centered Research and Reviews (JPCRR) is an open access, peer-reviewed medical journal focused on disseminating scholarly works devoted to improving patient-centered care practices, health outcomes, and the patient experience. 


\title{
I Live Alone but Don't Feel Alone: Social Isolation and Loneliness From the Patient Perspective
}

\author{
Julia Bedard-Thomas, MD, ${ }^{1,2}$ Christian Gausvik, MD, ${ }^{2}$ Jonathan Wessels, BS, ${ }^{1}$ Saundra Regan, $\mathrm{PhD},{ }^{1}$ \\ Keesha Goodnow, BAE, ${ }^{1}$ Anna Goroncy, MD ${ }^{1,2}$ \\ ${ }^{1}$ Department of Family and Community Medicine, University of Cincinnati, Cincinnati, $\mathrm{OH} ;{ }^{2}$ The Christ Hospital/University \\ of Cincinnati Family Medicine Residency, Cincinnati, $\mathrm{OH}$
}

\begin{abstract}
A growing homebound population may be at risk for social isolation and loneliness. Health-related social needs play a contributing role in these conditions. Research shows social isolation and loneliness are drivers of health outcomes. This pilot feasibility study seeks to explore patient-centered insight into perceptions of social isolation and loneliness in a homebound population. Eight participants were recruited from a home-based primary care practice within a family medicine residency program. One 30-minute semi-structured interview was completed in participants' homes. The interview focused on loneliness and social isolation, using the 6-item De Jong Gerveld loneliness scale. Three qualitative analysts open-coded transcriptions independently. Themes were defined using thematic analysis, then triangulated around a consensus of themes. Patients denied loneliness, but most described social isolation, highlighting the potential need for more targeted documentation and intervention in this arena. The most reported barrier affecting social isolation in our study population was mobility issues. The patient perspective is useful to focus the target of approach. Based on this pilot, additional research with a larger sample size across multiple sites is warranted to further explore homebound patients' experience of loneliness and social isolation in order to better guide assessment and interventions for these common problems. (J Patient Cent Res Rev. 2019;6:262-266.)
\end{abstract}

Keywords social isolation; loneliness; homebound persons; qualitative research; patient-centered care

S ocial isolation and feelings of loneliness are a reality for many older adults in the United States. This is highly pronounced for those limited to their homes by various physical and mental ailments and exacerbated by health-related social needs. These health-related social needs, including transportation, income, physical environment, and neighborhood safety, may each contribute to social isolation. Social isolation may be associated with poorer health outcomes and lead to feelings of loneliness. ${ }^{1}$ These feelings of loneliness can then go on to increase risk of dementia later in life, an already problematic and costly

Correspondence: Anna Goroncy, MD, University of Cincinnati Family Medicine Residency, 231 Albert Sabin Way, MSB 4010, Cincinnati, OH 45267-0504 (goroncar@ucmail.uc.edu) disease facing our nation's health systems. ${ }^{2}$ While loneliness and social isolation do not always overlap, ${ }^{3}$ loneliness manifests when there is a perceived lack of social engagement, and the circumstances of many homebound older adults put them at higher risk. ${ }^{4}$

The population of the United States is aging rapidly. According to the U.S. Census Bureau, adults older than 65 years will surpass the number of children under age 18 years by the year 2035. ${ }^{5}$ As the population ages, the number of homebound older adults will grow as well. ${ }^{6}$ Medicare defines homebound as being unable to leave the home without assistance under normal circumstances. ${ }^{7}$ This is most commonly the result of disability, injury, illness, sensory impairments, or cognitive decline. Homebound older adults make up close to $20 \%$ of new enrollees to AARP ${ }^{\circledR}$ Medicare supplement plans. ${ }^{8}$ The homebound segment is a significant and vulnerable part 
of our aging population and has been shown to have lower education and income levels, be at higher risk of depression and dementia, ${ }^{6}$ and be at high risk for social isolation and loneliness. ${ }^{9,10}$

The unmet social needs of homebound older adults are a well-examined area of research, ${ }^{11}$ and there is also an increasing abundance of research on how to treat loneliness. ${ }^{12}$ However, the literature lacks material on the perspectives of homebound patients towards their own social needs and how these needs may relate to loneliness. Home-based primary care provides an opportunity to better understand a person's social situation and address both social and medical factors influencing health. Understanding the perspectives of homebound older adults is vital to providing effective care for those experiencing unmet social needs, including social isolation that could lead to loneliness.

The goal of this pilot feasibility project was to explore the perspectives and experiences of loneliness and social isolation in homebound patients receiving home-based primary care.

\section{METHODS}

\section{Participants}

Participants were recruited from the home-based primary care (HBPC) practice within an urban hospitalbased residency clinic in the Midwest. This program accepts community-dwelling older adults determined by their primary health care providers to be homebound. At the time of recruitment, the HBPC practice included 27 active patients, ranging in age from 55 to 96 . Participants were selected as a convenience sample of those homebound patients. Nine HBPC patients and 1 caregiver were eligible and volunteered for participation. Two patients were hospitalized during the study period and therefore were not included in the study. The 8 remaining participants met the study criteria.

\section{Procedure}

This study was approved by the University of Cincinnati institutional review board and was part of a larger interview study about the social determinants of health in homebound older adults.

Participants completed the well-validated short-form 6 -item De Jong Gierveld loneliness scale (DJGLS). ${ }^{13}$ A semi-structured interview was conducted in the participants' homes. The interviewer asked about frequency of activity, types of activities, social support, leaving home, and other concepts associated with loneliness. The interview lasted about 30 minutes.

\section{Analysis}

The DJGLS assesses two components: emotional loneliness and social loneliness. Emotional loneliness refers to a lack of close relationships, whereas social loneliness speaks to a void of social support systems. The DJGLS is scored from 0 to 6 , with 0 being least lonely and 6 being most lonely.

Interviews were recorded, de-identified, and transcribed by the interviewer. Two qualitative analysts opencoded the transcriptions independently. Data were then recoded by a third analyst. Data were analyzed using thematic analysis and triangulated around a consensus of themes. Discrepancies in coding were decided by consensus among the three coding team members.

\section{RESULTS}

\section{Quantitative Results}

The first three items on the DJGLS are negatively worded, and the last three items are positively worded (Figure 1). Overall DJGLS scores revealed that 7 of 8 $(87.5 \%)$ respondents scored $0-3$ on the scale (Figure 2). Analysis of semi-structured interviews (Figure 3) confirmed that 8 of $8(100 \%)$ respondents reported feeling socially isolated, whereas less than half ( 2 of 7 , $29 \%$ ) of respondents admitted to feelings of loneliness.

\section{Thematic Analysis}

\section{Homebound Older Adults Experience Ongoing}

Social Isolation: Respondents described being unable to leave their home and how isolated they felt.

"It's been more than 5 months ... and it's crazy now where ... just try to get away from looking at these walls. I try to make myself sleep ... but when you suffer from insomnia you don't sleep, which means you go days looking at these walls. I'm on the verge of jumping out the window."

Respondents reported the feeling of being unable to leave their homes or only leaving to go to doctor appointments, sometimes for months: "Well this month, I've only been out [of the house] once." One patient described his feeling of isolation even though he is located in the city and lives in a subsidized senior living 


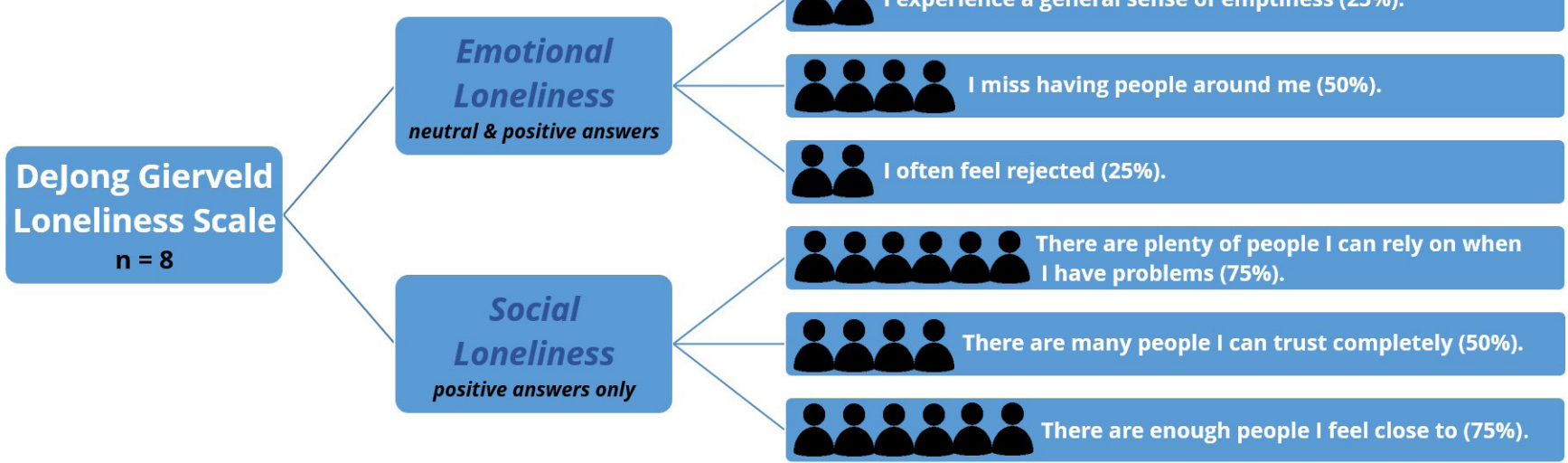

Figure 1. De Jong Gierveld loneliness scale breakdown for patient responses ( $n=8)$.

\section{DEJONG GIERVELD LONELINESS SCALE: Interpretation of results $n=8$}

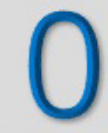

Least lonely

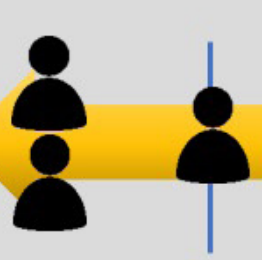

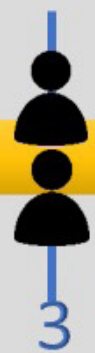
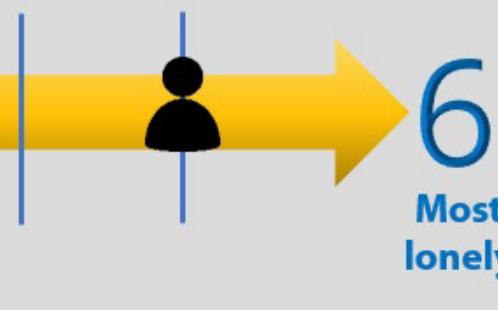

Most

lonely

Figure 2. Distribution of patient scores $(n=8)$ on De Jong Gierveld loneliness scale.

Figure 3.

Semi-structured interview questions.
Tell me how you would define loneliness.

What makes you feel isolated or withdrawn?

What makes you feel like part of a group?

What gets in the way of being as social as you would like to be?

Tell me about people you feel close to. How often do you talk with them? Do you wish it was more?

In an average week, how many days do you leave home?

When you do leave home, where do you go?

What did you enjoy doing when leaving your home was easier? What was your social life like when you left your home more?

What do you enjoy doing now?

In an average week, how often do you have visitors?

In an average week, how often do you feel alone?

What else would you like to share? 
apartment: "You feel isolated ... like I'm living out in the boondocks somewhere and hardly ever see anybody ... not being able to get out and go where I need to."

Barriers to Social Engagement: Respondents discussed multiple barriers to social engagement, including disabilities, chronic medical problems, and mobility limitations. Assistive devices, though meant to increase independence, also were described as hindrances for these respondents, as all relied on public or insuranceprovided transportation.

"I don't go anywhere anymore because I can't walk. Only to the doctor and my insurance sends a ride to get me."

"I need to go shopping, but getting around is mission impossible. I don't have nobody can take me in my motorized chair."

Though respondents all live in an urban area, transportation was reported by many as a major barrier to social engagement.

"I used to go to the $Y$ on the weekend ... I miss going to the $Y$, exercising. My grandson took my car cause he don't want me to drive anymore ... when I want to go someplace I gotta call."

"I'm not used to having to ask people to do anything for me ... and when you call someone they say they'll do it. But oh something came up and they'll do it this weekend. I needed it now, not this weekend."

This theme thread revealed a common challenge of relying on others and a loss of independence. Respondents had little control over receiving help from others, even those they considered their social support.

Socially Isolated Homebound Adults Do Not Necessarily Feel Lonely: Respondents were asked to define loneliness and whether or not they feel lonely. About $71 \%$ of respondents said they did not feel lonely. They could define loneliness but did not experience it.

"I don't ever feel alone, I swear I can't say I ever feel alone. I live alone but don't feel alone."

A few respondents described a sad, isolated feeling and being unable to engage with friends and family.

"Loneliness is a sad feeling of not having anyone. And I guess the reason I don't feel lonely is, I mean,
I do have someone. It might not be on my time schedule, but there is someone there for me."

\section{Phone Calls for Homebound Patients Are Important}

Part of Social Support: The theme of social support was useful in disentangling the themes of social isolation and loneliness. Those who had family and friends described phone calls as the major social support in their daily lives rather than visits in person. One patient stated, "I mean, if I start to feel lonely I'll call my son, text my daughter, or call my mom." Two people described no interaction with friends and family at all.

"I'm no longer married, my child is dead, my wife is dead, my parents are dead. ... I have no brothers or sisters ... you just learn to deal with it."

"My social life, it was great, it was good ... but then you get like this, it starts going down, stopped socializing, I moved here, sold my house. And I don't keep in contact with a lot of people... I threw my phone book away (accidentally) ... but life goes on."

Patients' descriptions of social isolation centered on the ability to get out of their homes or having visits with friends or family. Leaving their homes entailed relying on friends or family, which many described not being able to do. Most respondents could not afford private transportation, and insurance-provided transportation was for medical appointments only. Loss of functional independence was a commonly elicited barrier to maintaining a desired social life.

\section{DISCUSSION}

This study was conducted to explore the perspectives and experiences of loneliness and social isolation in homebound patients receiving home-based primary care. It is novel in its first-hand, patient-focused perspective. Per our data, social isolation relates mostly to physical and environmental barriers, including neighborhood safety, disability and need for assistive devices, and transportation. Loneliness is a less concrete, subjective feeling that relates to factors such as loss of friends, inability to socialize in person, a lack of family support, and fewer human interactions.

One strength of this study is direct, patient-centered data collection. The semi-structured nature of the interview allowed for elicitation of a broad variety of perspectives within a heterogenous patient population. 
This small convenience sample of patients from only one institutional program is a limitation that prevents generalizable conclusions from being made.

As health care professionals work to address complex needs of patients, social factors will continue to play a large role. In vulnerable groups, such as this homebound population, the impact of social factors is even more apparent. In our study population, social isolation was more prevalent than loneliness, thus highlighting the potential need for more targeted documentation and intervention in this arena. The patient perspective is useful when focusing the target of the approach. There are models of care that screen for "social connections and social isolation" within an electronic medical record system, highlighting this domain as a psychosocial "vital sign." 14 Innovative interventions are waiting to be developed and implemented in health systems to optimize care of homebound patients.

Based on this pilot feasibility study, additional research with a larger sample size across multiple sites is warranted to further examine homebound patients' experience of loneliness and social isolation to better guide assessment and interventions for these common problems. Exploring homebound patients' social isolation is important to maintaining not only the mental and physical health of patients but also their quality of life.

\section{Patient-Friendly Recap}

- Some evidence suggests that feelings of loneliness and social isolation (ie, lack of contact between an individual and society) result in poorer health outcomes.

- Through home-based interviews, the perspectives of homebound primary care patients regarding their social needs and selfdescribed loneliness were obtained.

- Homebound patients felt socially isolated more so than lonely. The authors recommend social isolation be documented and serve as a focal point of future research into this population.

\section{Author Contributions}

Study design: Bedard-Thomas, Regan, Goodnow, Goroncy. Data acquisition or analysis: all authors. Manuscript drafting: all authors. Critical revision: Goodnow, Goroncy.

\section{Conflicts of Interest}

None.

\section{Funding Sources}

This work was supported by a Primary Care Training and Enhancement grant (T0BHP28567; "Partnering with Underserved Patients: A Novel Health Transformation Curriculum") from the Health Resources and Services Administration (Rockville, MD).

\section{References}

1. Tomaka J, Thompson S, Palacios R. The relation of social isolation, loneliness, and social support to disease outcomes among the elderly. J Aging Health. 2006;18:359-84. CrossRef

2. Holwerda TJ, Deeg DJ, Beekman AT, et al. Feelings of loneliness, but not social isolation, predict dementia onset: results from the Amsterdam Study of the Elderly (AMSTEL). J Neurol Neurosurg Psychiatry. 2014;85:135-42. CrossRef

3. Medvene LJ, Nilsen KM, Smith R, et al. Social networks and links to isolation and loneliness among elderly HCBS clients. Aging Ment Health. 2016;20:485-93. CrossRef

4. Cohen-Mansfield J, Shmotkin D, Hazan H. Homebound older persons: prevalence, characteristics, and longitudinal predictors. Arch Gerontol Geriatr. 2012;54:55-60. CrossRef

5. Vespa J, Armstrong DM, Medina L. Demographic turning points. Population projections for the United States: 2020 to 2060. https:/www.census.gov/content/dam/Census/newsroom/presskits/2018/jsm/jsm-presentation-pop-projections.pdf. Washington, DC: U.S. Census Bureau, 2018. Accessed January 9, 2019.

6. Ornstein KA, Leff B, Covinsky KE, et al. Epidemiology of the homebound population in the United States. JAMA Intern Med. 2015;175:1180-6. CrossRef

7. CMS.gov. Glossary, homebound. https://www.cms.gov/apps/ glossary/search.asp?Term=homebound\&Language=English. Baltimore, MD: U.S. Centers for Medicare \& Medicaid Services. Accessed December 20, 2018.

8. Musich S, Wang SS, Hawkins K, Yeh CS. Homebound older adults: prevalence, characteristics, health care utilization and quality of care. Geriatr Nurs. 2015;36:445-50. CrossRef

9. Qiu WQ, Dean M, Liu T, et al. Physical and mental health of homebound older adults: an overlooked population. $J \mathrm{Am}$ Geriatr Soc. 2010;58:2423-8. CrossRef

10. Goll JC, Charlesworth G, Scior K, Stott J. Barriers to social participation among lonely older adults: the influence of social fears and identity. PLoS One. 2015;10:e0116664. CrossRef

11. Steptoe A, Shankar A, Demakakos P, Wardle J. Social isolation, loneliness, and all-cause mortality in older men and women. Proc Natl Acad Sci U S A. 2013;110:5797-801. CrossRef

12. Masi CM, Chen HY, Hawkley LC, Cacioppo JT. A metaanalysis of interventions to reduce loneliness. Pers Soc Psychol Rev. 2011;15:219-66. CrossRef

13. De Jong Gierveld J, van Tilburg TG. A 6-item scale for overall, emotional, and social loneliness confirmatory tests on survey data. Res Aging. 2006;28:582-98. CrossRef

14. Perissinotto C, Holt-Lunstad J, Periyakoil VS, Covinsky K. A practical approach to assessing and mitigating loneliness and isolation in older adults. J Am Geriatr Soc. 2019;67:657-62. $\underline{\text { CrossRef }}$

(C) 2019 Aurora Health Care, Inc. 